\title{
Novel Miniaturized Octaband Antenna for LTE Smart Handset Applications
}

\author{
Haixia Liu, Bo Lu, and Long Li \\ School of Electronic Engineering, Xidian University, Xian, Shaanxi 710071, China \\ Correspondence should be addressed to Long Li; longliee@foxmail.com
}

Received 27 February 2015; Revised 30 April 2015; Accepted 5 May 2015

Academic Editor: Jaume Anguera

Copyright (C) 2015 Haixia Liu et al. This is an open access article distributed under the Creative Commons Attribution License, which permits unrestricted use, distribution, and reproduction in any medium, provided the original work is properly cited.

\begin{abstract}
A novel octaband LTE mobile phone antenna is presented, which has a compact size with the overall dimension of $35 \mathrm{~mm} \times 9 \mathrm{~mm} \times$ $3 \mathrm{~mm}$. The miniaturized octaband antenna is implemented by a simple prototype of three parts which include a folded monopole as feeding element, main radiator element, and parasitic radiator element. The main and parasitic radiator elements are excited by the folded monopole feeding element coupling and shorting to the handset ground plane. A wide bandwidth in low-frequency bands covering from $747 \mathrm{MHz}$ to $960 \mathrm{MHz}$ (LTE Band13/GSM850/GSM900) is contributed by both main and parasitic radiator elements. In addition, the folded monopole is designed to resonate at $2530 \mathrm{MHz}$, and the coupling between the feeding element and main radiator element is designed to resonate at $1840 \mathrm{MHz}$. Subsequently, the wide bandwidth in high-frequency bands covering from $1710 \mathrm{MHz}$ to $2690 \mathrm{MHz}$ (DCS1800/PCS1900/WCDMA2100/LTE2300/LTE2500) is contributed by both structures. The antenna has the total efficiency up to $30 \%$ in low bands and up to $75 \%$ in high bands, respectively. At the same time, the proposed miniaturized octaband LTE mobile phone antenna is fabricated and tested to verify the design.
\end{abstract}

\section{Introduction}

Nowadays, with the rapid development of wireless communication technology, there is a great demand for high-performance, multifunction, slight, and thin wireless terminal products. Therefore, it gives rise to a challenging demand for miniaturized, low-profile, broadband, high-efficiency, highly integrated, and low-cost antennas [1-6]. With the development and promotion of the LTE standards, the smart mobile phones will be popular and widely used, and the design of new LTE antenna has been becoming a research hotspot. It is worth noting that the LTE mobile antennas should have wideband characteristics covering the working frequency bands of $2 \mathrm{G}, 3 \mathrm{G}$, and $4 \mathrm{G}$, which further increase the difficulty of cell phone antenna design [4-7]. Some kinds of miniaturized LTE handset antennas are proposed in [8-14]. Simultaneously, some design methods of decreasing antenna dimension and improving antenna performance were adopted [9-16]. An electrically small, wideband, and $4 \mathrm{G}$ handset antenna printed on a ceramic material with a high relative permittivity of 6.45 is reported in [9], where the dimension of the antenna is $35 \mathrm{~mm} \times 11 \mathrm{~mm} \times 5 \mathrm{~mm}$. But the material with high relative permittivity may lead to some undesired loss and the increase of cost. It is demonstrated that meander-line is suitable for miniaturizing dimension of the LTE handset antenna [10-13]. A planar printed antenna with folded monopole and folded shorting strip to cover the frequency bands of $698-960 \mathrm{MHz}$ and $1710-2690 \mathrm{MHz}$ is reported in [10], and the whole dimension of the antenna is $64 \mathrm{~mm} \times 15 \mathrm{~mm}$. The antenna with dimension of $40 \mathrm{~mm} \times$ $15 \mathrm{~mm} \times 3 \mathrm{~mm}$ is presented in [11], which has three wide operating bands $698-960 \mathrm{MHz}, 1710-2690 \mathrm{MHz}$, and $5150-$ $5825 \mathrm{MHz}$. Integrating lumped components into the antenna is another way to achieve miniaturization $[8,12-15]$. A series chip capacitor $(C)$ of $1.2 \mathrm{pF}$ and a series chip inductor of $5.6 \mathrm{nH}$ were used as matching circuit in the front of the antenna in [12] and a wide frequency band from 704 to $960 \mathrm{MHz}$ and 1710 to $2690 \mathrm{MHz}$ can be obtained. The area of the antenna is $34.5 \mathrm{~mm} \times 10 \mathrm{~mm}$, but the antenna is mounted along an edge and at a corner of the device ground plane of size $150 \times 200 \mathrm{~mm}^{2}$, which is a reasonable size for the tablet computer with a 10 in display panel. Table 1 gives 
TABLE 1: Comparison of the dimension, working bandwidth, and radiation efficiency of the antennas reported in references.

\begin{tabular}{|c|c|c|c|c|}
\hline References & $\begin{array}{c}\text { Dimension of } \\
\text { substrate }\left(\mathrm{mm}^{3}\right)\end{array}$ & $\begin{array}{c}\text { Dimension of } \\
\text { antenna }\left(\mathrm{mm}^{3}\right)\end{array}$ & Frequency $(\mathrm{MHz})$ & $\begin{array}{l}\text { Radiation } \\
\text { efficiency }\end{array}$ \\
\hline [3] & $100 \times 60 \times 0.8$ & $9.5 \times 60 \times 3$ & $698-960,1710-2690$ & $\begin{array}{l}52-75 \%(\mathrm{~L}) \\
53-78 \%(\mathrm{H})\end{array}$ \\
\hline$[6]$ & $122 \times 46 \times 1$ & $11 \times 46 \times 7$ & $698-960,1710-2690$ & $\begin{array}{l}55.3-71.3 \%(\mathrm{~L}) \\
32.5-98.1 \%(\mathrm{H})\end{array}$ \\
\hline$[7]$ & $115 \times 40 \times 1$ & $15 \times 40 \times 1$ & $685-1345,1685-2985$ & $\begin{array}{l}50-70 \%(\mathrm{~L}) \\
50-82 \%(\mathrm{H})\end{array}$ \\
\hline$[8]$ & $110 \times 55 \times 1$ & $12 \times 55 \times 4$ & $809-975,1675-2703$ & $\begin{array}{l}24 \%-44 \%(\mathrm{~L}) \\
40 \%-78 \%(\mathrm{H})\end{array}$ \\
\hline$[12]$ & $150 \times 200 \times 0.8$ & $10 \times 34.5 \times 0.8$ & $704-960,1710-2690$ & $\begin{array}{l}40 \%-62 \%(\mathrm{~L}) \\
64 \%-92 \%(\mathrm{H})\end{array}$ \\
\hline
\end{tabular}

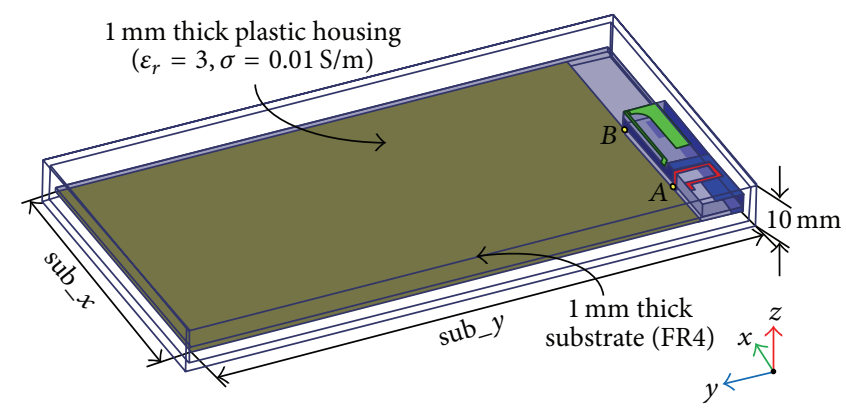

$A$ : feeding point

$B$ : shorting point

Figure 1: Overall structure of the proposed octaband LTE handset antenna.

the comparison of the dimension, working bandwidth, and radiation efficiency of the reported references.

Among these presented small-size LTE antennas, the methods of mender-line, lumped components, and high relative permittivity are applied to achieve the characteristics of miniature, low-profile, and high performance. In this paper, a new miniaturized octaband antenna for LTE smart mobile phone is introduced. The proposed antenna consists of three parts: the folded monopole feeding element, main radiator shorting element, and the parasitic radiator shorting element. It has a compact size with the overall dimension of $9 \mathrm{~mm} \times$ $35 \mathrm{~mm} \times 3 \mathrm{~mm}$. Additionally, the parasitic radiator element is loaded with a lumped inductance of $4.7 \mathrm{nH}$, which can reduce the length of the antenna with good matching. Wide octaband operating bands covering the LTE Band13/GSM850/GSM900/ DCS1800/PCS1900/WCDMA2100/LTE2300/LTE2500 (747$960 \mathrm{MHz}, 1710-2690 \mathrm{MHz}$ ) can be obtained. The paper is arranged as follows. Section 2 will introduce the geometry and configuration of the proposed miniaturized LTE antenna. The operating mechanism of the proposed antenna is analyzed in Section 3. Moreover, the miniaturized LTE antenna is fabricated and measured. The measured and simulated results indicate the good performance of the proposed antenna. Finally, a conclusion is given in Section 4.

\section{Antenna Design}

The overall structure of the proposed new miniaturized octaband LTE handset is shown in Figure 1. The total dimension of the substrate is $60 \mathrm{~mm} \times 120 \mathrm{~mm}$, which is suitable for the actual smart handset platform. The $1 \mathrm{~mm}$ thick FR4 substrate with relative permittivity 4.4 and loss tangent 0.024 is used as the system circuit board. The proposed antenna is mounted on a $3 \mathrm{~mm}$ thick antenna holder that is also made of FR4 material. Note that a plastic casing made of a $1 \mathrm{~mm}$ thick plastic plate with relative permittivity 3.0 and loss tangent 0.02 encloses the system circuit board to simulate the practical mobile phone casing [7]. Figure 2 shows $3 \mathrm{D}$ view of the proposed octaband handset antenna and the detailed 2D topology. Note that the red dash-lines shown in Figure 2(b) represent the bending lines. The proposed antenna has a compact size with an overall volume of $35 \mathrm{~mm} \times 9 \mathrm{~mm} \times$ $3 \mathrm{~mm}$, which is smaller than the proposed antennas in Table 1.

The proposed antenna has a simple structure. Table 2 shows the structural parameters in detail. It consists of a folded monopole feeding element, a main radiator element, and a parasitic radiator element. The folded monopole operates at upper band about $2530 \mathrm{MHz}$. The main and parasitic radiator elements are excited by the folded monopole feeding element coupling and shorting to the handset ground plane. 


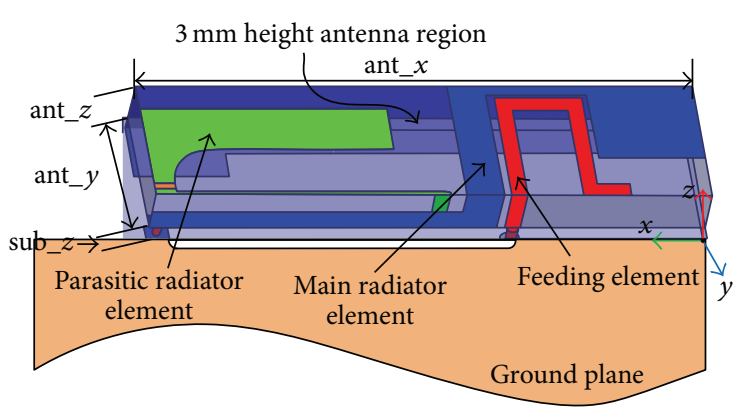

(a)

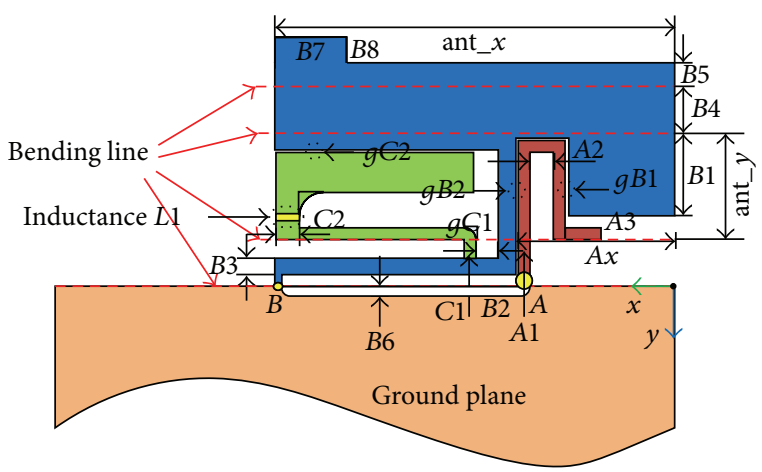

(b)

FIGURE 2: Configuration of the proposed octaband handset antenna, (a) 3-dimensional view and (b) 2-dimensional view (red dash-lines represent the bending lines).

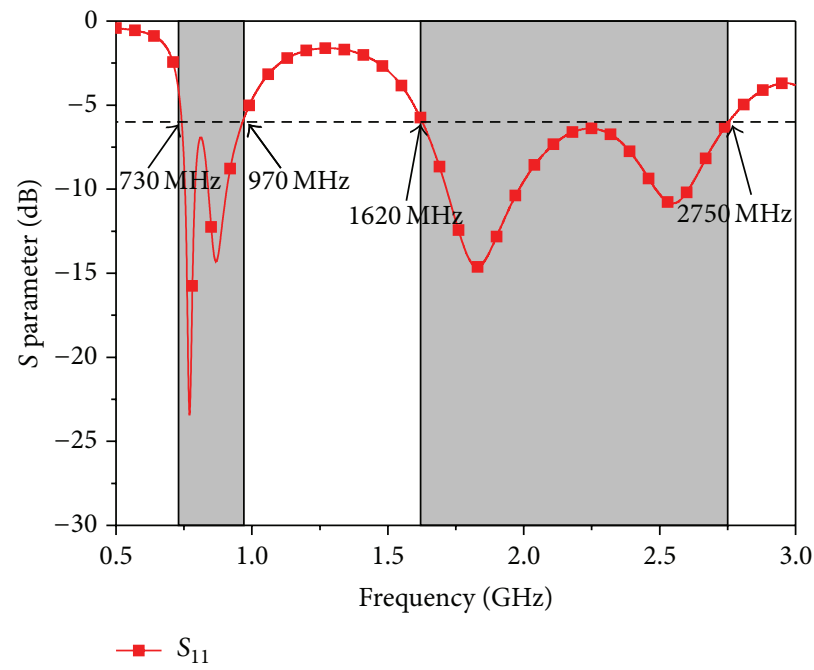

FIGURE 3: Simulated $S$ parameter for proposed antenna.

TABLE 2: Detailed structural parameters of the proposed antenna (unit: $\mathrm{mm}$ ).

\begin{tabular}{lcccccc}
\hline ant_$\_$ & ant_$y$ & ant_z & $A x$ & $A 1$ & $A 2$ & $A 3$ \\
\hline 35 & 9 & 3 & 12.6 & 1 & 3.5 & 2 \\
\hline$g B 1$ & $B 1$ & $g B 2$ & $B 2$ & $B 3$ & $B 4$ & $B 5$ \\
\hline 0.35 & 5.95 & 0.5 & 2.35 & 1.5 & 4 & 2 \\
\hline$B 6$ & $B 7$ & $B 8$ & $C 1$ & $g C 1$ & $C 2$ & $g C 2$ \\
\hline 0.7 & 6 & 2 & 1 & 1 & 1.35 & 0.6 \\
\hline
\end{tabular}

The sub $z$ is referred to as the thickness of substrate, that is, $1 \mathrm{~mm}$. The main radiator element can be excited by the capacitive coupling and generate a resonant mode at about $770 \mathrm{MHz}$, and the parasitic radiator element is also excited about $860 \mathrm{MHz}$. A lumped inductor $(4.7 \mathrm{nH})$ is embedded in the parasitic radiator element to further reduce the size. A similar concept of using a short driven element coupled to a parasitic element was proposed for achieving operation at $2 \mathrm{G}$ and $3 \mathrm{G}$ bands in [17]. More importantly, the etched slit on the ground plane and the shorting strip with the truncated corners are adopted to achieve a good impedance matching. And the etched ground plane can be regarded as a part of the antenna in order to realize the miniaturization. Therefore, a wide bandwidth covering lower frequency bands from $747 \mathrm{MHz}$ to $960 \mathrm{MHz}$ (LTE Band13/ GSM850/GSM900) can be obtained. The strong capacitive coupling between the folded monopole and the main radiator element can generate a resonant mode at about $1840 \mathrm{MHz}$, which combines with the high resonant mode contributed by the folded monopole at $2530 \mathrm{MHz}$ to produce wide highfrequency bands from 1710 to $2690 \mathrm{MHz}$ (covering DCS1800/ PCS1900/WCDMA2100/LTE2300/LTE2500). Therefore, the proposed antenna can cover the octaband operation in the 747-960 MHz and 1710-2690 MHz.

\section{Results and Discussion}

Figure 3 shows the simulated $S$ parameter of the proposed antenna by using Ansys HFSS software based on finiteelement full-wave analysis. It is clearly shown that a wide low-frequency band from $747 \mathrm{MHz}$ to $960 \mathrm{MHz}$ can be 


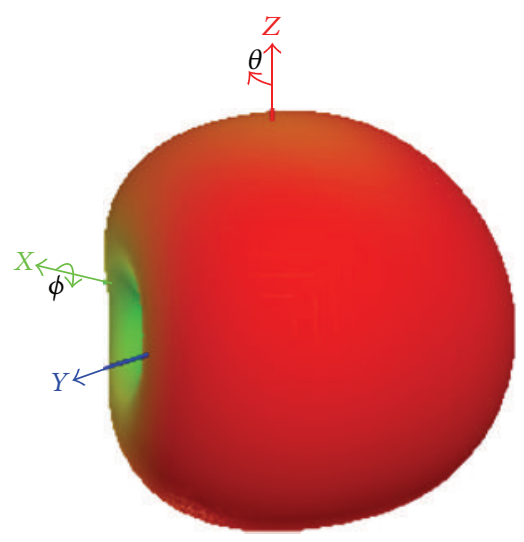

(a)

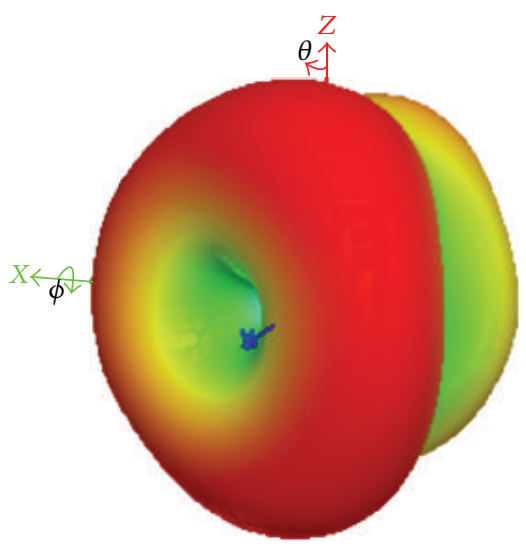

(c)

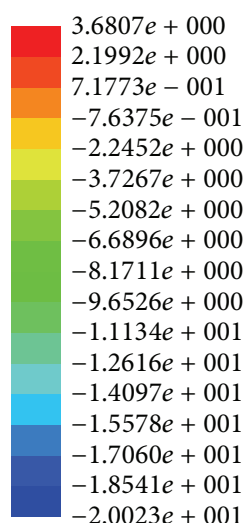

$2.0023 e+001$

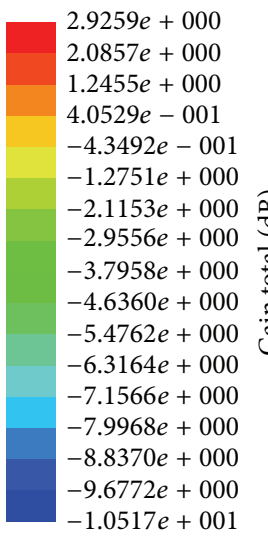

$-1.0517 e+001$

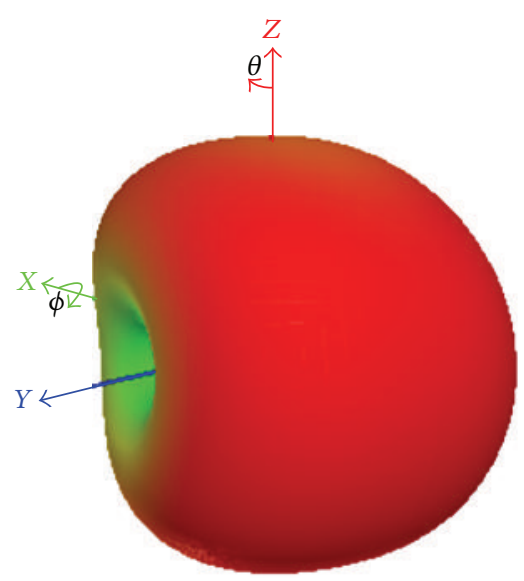

(b)

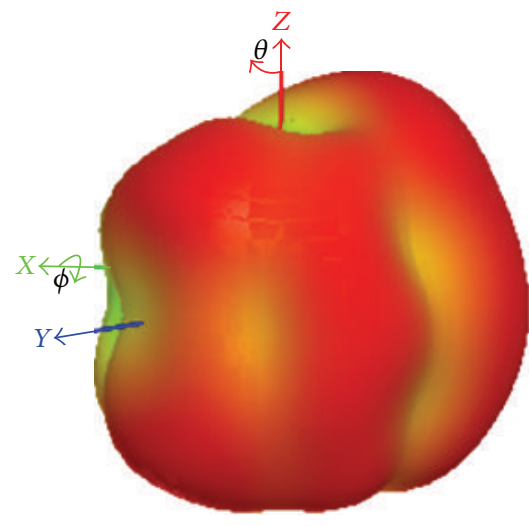

(d)

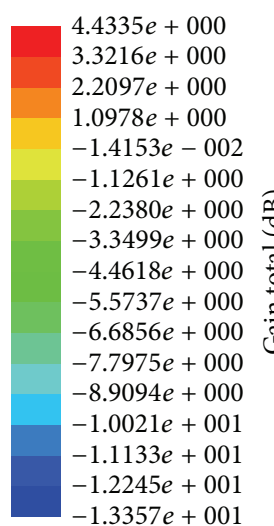

$-1.3357 e+001$

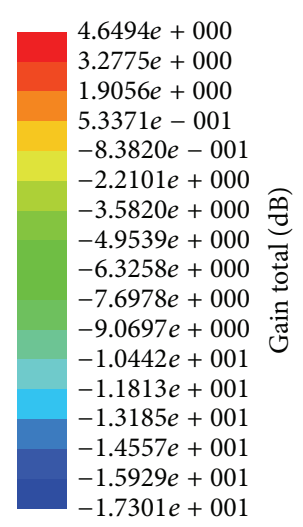

$-1.7301 e+001$

Figure 4: Simulated three-dimensional radiation patterns of proposed antenna, (a) $770 \mathrm{MHz}$, (b) $860 \mathrm{MHz}$, (c) $1840 \mathrm{MHz}$, and (d) $2530 \mathrm{MHz}$.

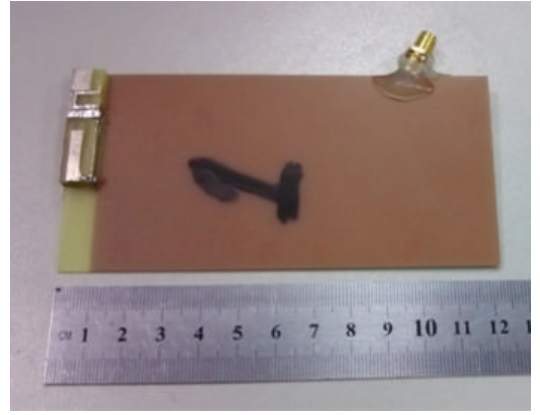

(a)

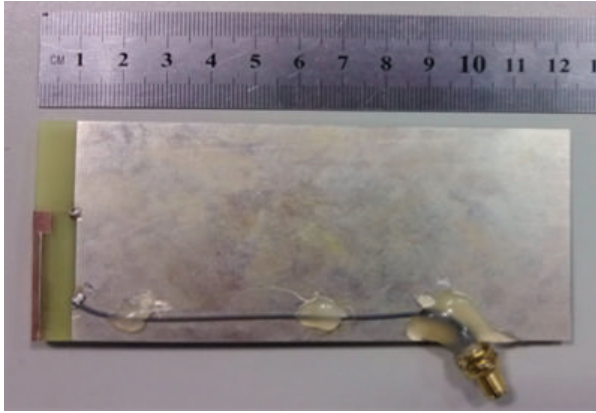

(b)

FIgURE 5: Prototype of the fabricated LTE handset antenna, (a) front view and (b) back view.

obtained based on the definition of $-6 \mathrm{~dB} S_{11}$ in the handset application. This allows the antenna to cover the LTE Band13/ GSM850/GSM900 operation. Simultaneously, a wide highfrequency band from 1710 to $2690 \mathrm{MHz}$ can be achieved. Therefore, the octaband operation of the LTE Band13/GSM 850/GSM900/DCS1800/PCS1900/WCDMA2100/LTE 2300/ LTE2500 can be obtained for the proposed antenna.
The simulated three-dimensional radiation patterns of the proposed antenna are shown in Figure 4 and the characteristics of omnidirectional radiation can be achieved.

The proposed octaband miniaturized LTE antenna prototype was fabricated and tested, as shown in Figure 5. The simulated results were obtained by the Ansys HFSS and the measured results were tested by an Agilent 8719ES 


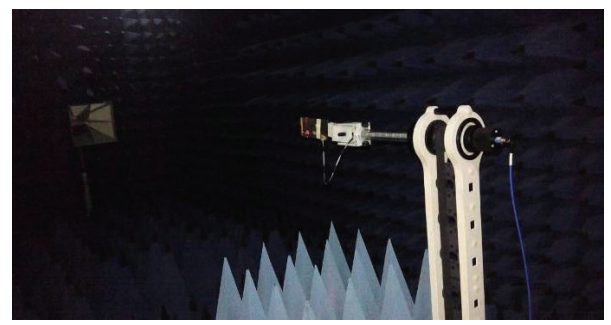

FIGURE 6: Test environment of LTE handset antenna in microwave anechoic chamber.

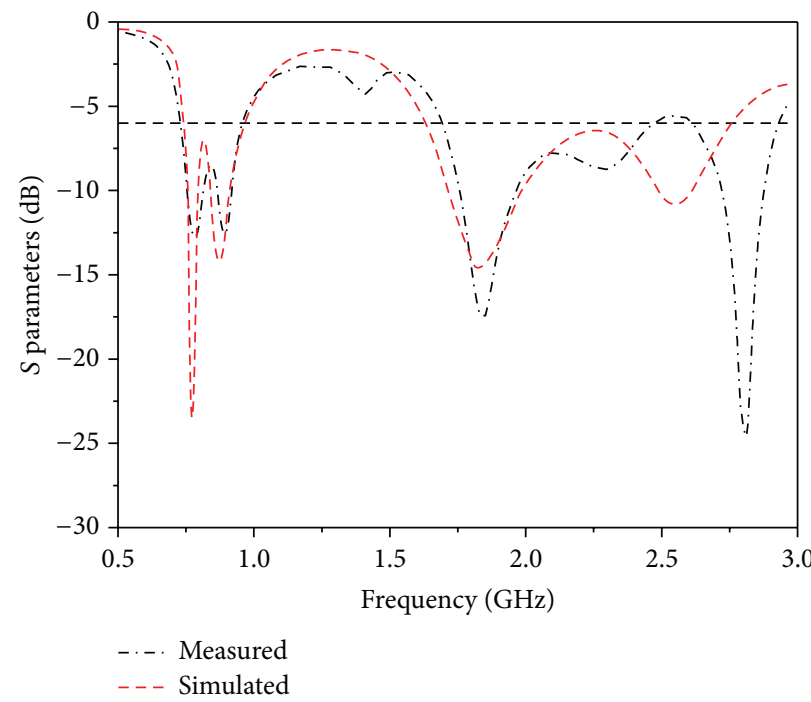

FIGURE 7: Comparison of simulated and measured $S_{11}$.

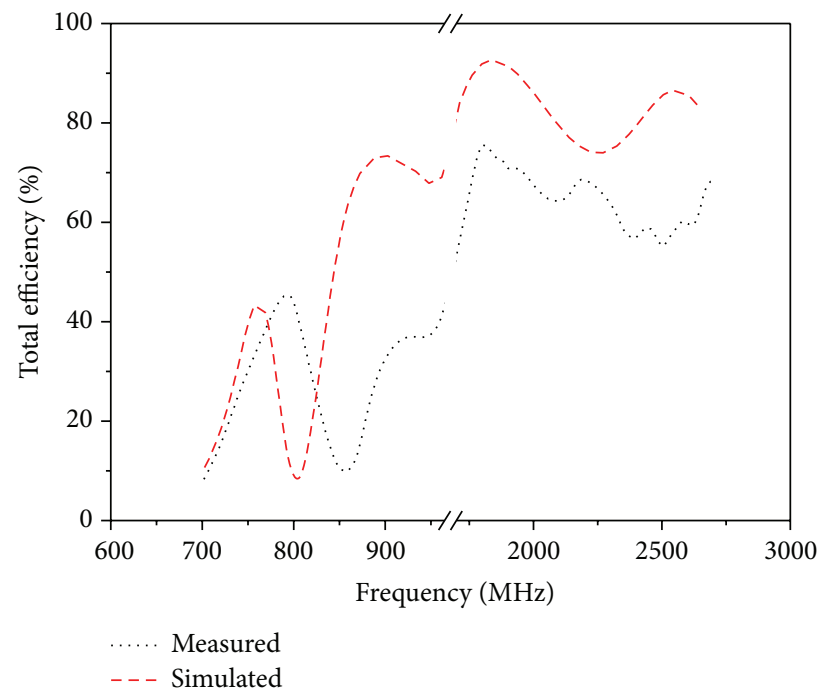

Figure 8: Comparison of simulated and measured total antenna efficiency.

vector network analyzer in a microwave anechoic chamber. Test environment of LTE handset antenna is shown in Figure 6. Figure 7 shows the comparison of the simulated and measured $S_{11}$ of the antenna, and the good agreements are obtained between the measured and simulated results.
It is noteworthy that an additional resonance is produced at $2750 \mathrm{MHz}$, possibly because of the strong capacitive coupling of the radiation strips. The measured total antenna efficiency and three-dimensional radiation patterns of the proposed antenna are shown in Figures 8 and 9, respectively. It can 


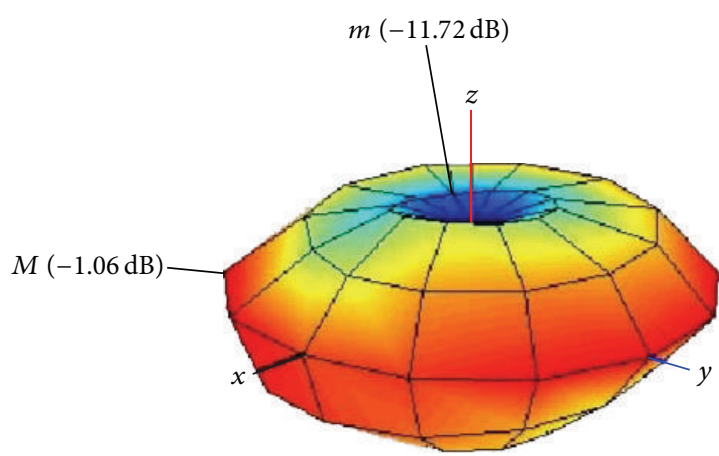

(a)

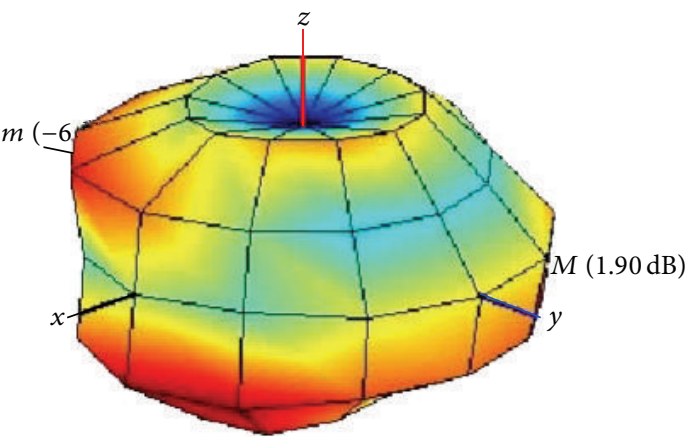

(c)

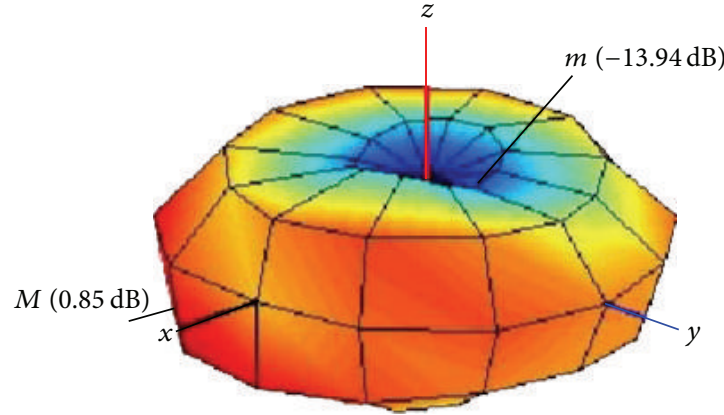

(b)

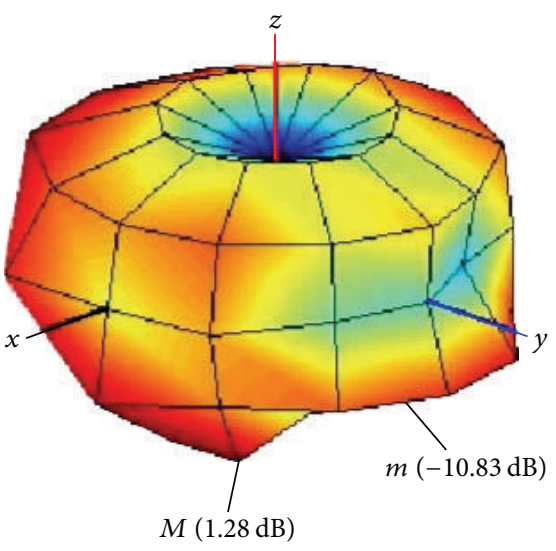

(d)

FiguRE 9: Measured three-dimensional radiation patterns of proposed antenna, (a) $767 \mathrm{MHz}$, (b) $885 \mathrm{MHz}$, (c) $1806 \mathrm{MHz}$, and (d) $2500 \mathrm{MHz}$.

be seen that the measured total efficiency of the antenna has some degradation and shift compared to the simulated results. The main reason is due to the material loss and fabrication errors. A surface-mount technology chip inductor of $4.7 \mathrm{nH}$ (LQW15AN4N7B00D) was used, which is from Murata Manufacturing Co., Ltd. Because the inductor losses were not considered in the simulation, the measured results have some difference with the simulated results. Overall, the total efficiency of the proposed antenna is up to $75 \%$ in upper bands and up to $30 \%$ in lower bands. It can be seen from Figure 9 that the measured 3D radiation patterns of the antenna are close to omnidirectional radiation characteristics.

In order to analyze the characteristics of the proposed antenna in detail, the surface current distributions on the antenna and ground plane at the different operating frequencies are shown in Figure 10. It is clearly observed that the current is mainly distributed on the main radiator shorting element at $770 \mathrm{MHz}$, as shown in Figure 10(a), and on the parasitic radiator shorting element at $860 \mathrm{MHz}$, as shown in Figure 10(b). It can be seen that both main and parasitic radiator elements are excited to cover a broadband frequency range from $747 \mathrm{MHz}$ to $960 \mathrm{MHz}$. The strong surface current on the folded monopole can be seen at $2530 \mathrm{MHz}$, as shown in Figure 10(d), which demonstrates that the mode is contributed by the folded monopole. Moreover, the surface current between the folded monopole and the main radiator element is strengthened at $1840 \mathrm{MHz}$, as shown in Figure 10(c), which proves that the resonant mode is excited. Thus, a wide operating band from $1710 \mathrm{MHz}$ to $2690 \mathrm{MHz}$ can be obtained.

\section{Conclusions}

In this paper, a new miniaturized LTE handset antenna is designed, fabricated, and measured, which exhibits an octaband operation in LTE Band13/GSM850/GSM900/DCS 1800/ PCS1900/LTE2300/LTE2500 (747 MHz-960 MHz, $1710 \mathrm{MHz}-$ $2690 \mathrm{MHz}$ ) with high performance. It has a compact size with overall dimensions of $35 \mathrm{~mm} \times 9 \mathrm{~mm} \times 3 \mathrm{~mm}$, which is smaller than the reported handset antenna. The antenna efficiency is generally larger than $30 \%$ in lower band and larger than $75 \%$ in upper band. It is worth pointing out that the proposed miniaturized octaband LTE antenna can be suitable for the application of next generation of wireless communications.

\section{Conflict of Interests}

The authors declare that there is no conflict of interests regarding the publication of this paper. 

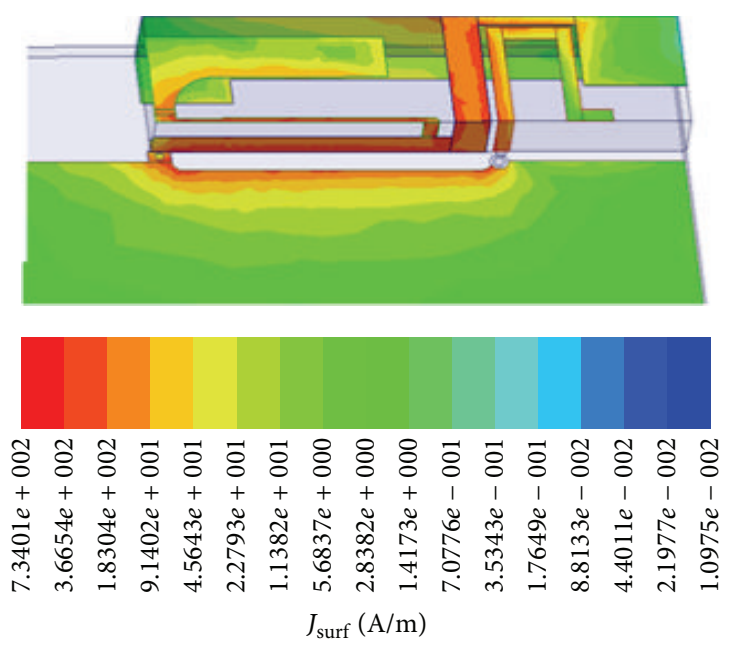

(a)
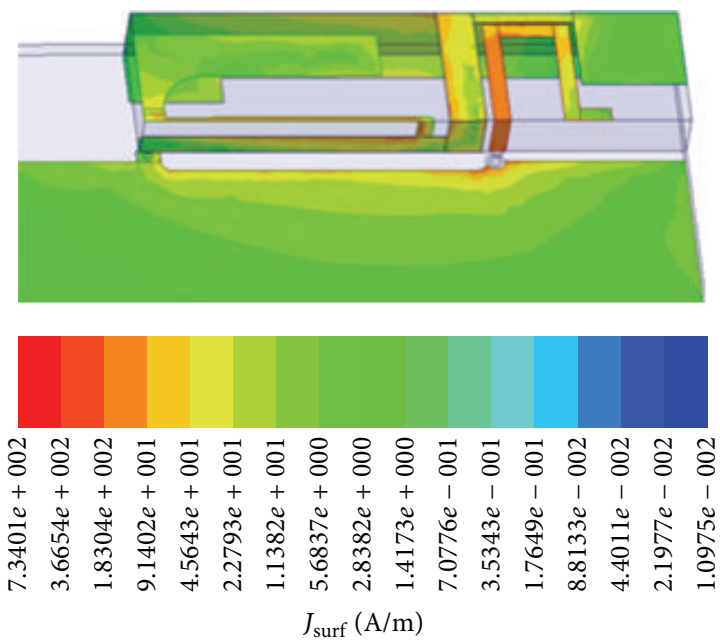

(c)
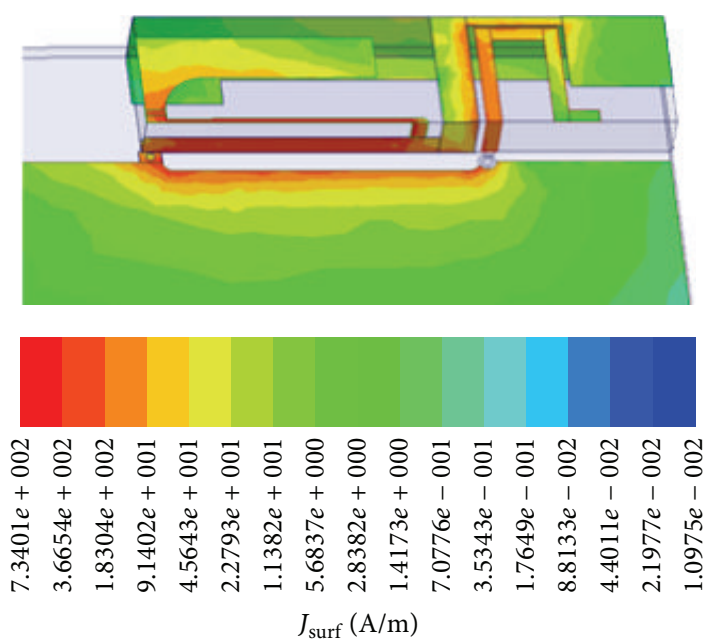

(b)
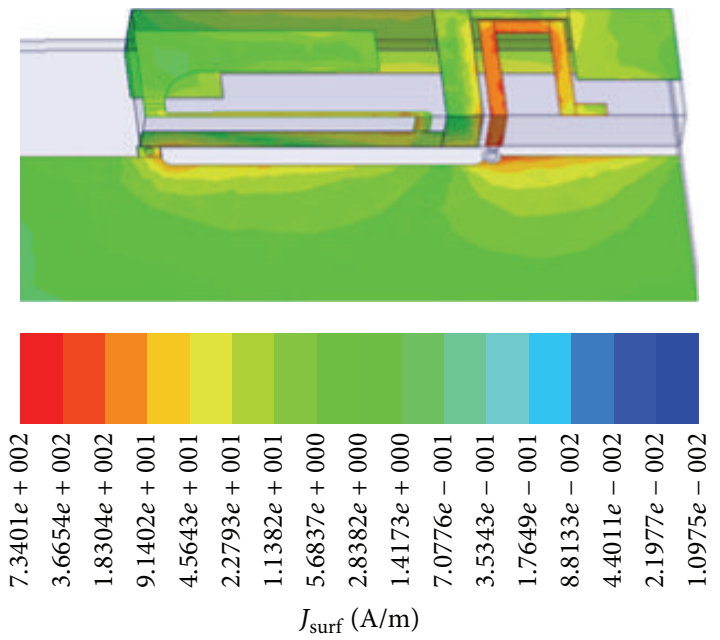

(d)

FIGURE 10: Characteristics of the current distribution on the antennas and ground plane, (a) $770 \mathrm{MHz}$, (b) $860 \mathrm{MHz}$, (c) $1840 \mathrm{MHz}$, and (d) $2530 \mathrm{MHz}$.

\section{Acknowledgments}

This work is supported by National Natural Science Foundation of China under Contract no. 51477126 and supported partly by Natural Science Basic Research Plan in Shaanxi Province of China (no. 2013JZ019), Technology Innovation Research Project of the CETC, and Fundamental Research Funds for the Central Universities (K5051202051, K5051302025).

\section{References}

[1] M. Kim, W. Lee, W. Kim, and Y. J. Yoon, "A multi-band internal antenna for all commercial mobile communication bands and $802.11 \mathrm{a} / \mathrm{b} / \mathrm{g} / \mathrm{n}$ WLAN," in Proceedings of the Asia-Pacific Microwave Conference (APMC '11), pp. 171-174, Melbourne, Australia, December 2011.

[2] J. Villanen, J. Ollikainen, O. Kivekäs, and P. Vainikainen, "Coupling element based mobile terminal antenna structures," IEEE
Transactions on Antennas and Propagation, vol. 54, no. 7, pp. 2142-2153, 2006.

[3] K.-L. Wong, W.-Y. Chen, C.-Y. Wu, and W.-Y. Li, "Small-size internal eight-band LTE/WWAN mobile phone antenna with internal distributed LC matching circuit," Microwave and Optical Technology Letters, vol. 52, no. 10, pp. 2244-2250, 2010.

[4] J. Anguera, A. Andújar, M.-C. Huynh, C. Orlenius, C. Picher, and C. Puente, "Advances in antenna technology for wireless handheld devices," International Journal of Antennas and Propagation, vol. 2013, Article ID 838364, 25 pages, 2013.

[5] Y.-L. Ban, J.-H. Chen, J. L.-W. Li, and Y. Wu, "Small-size printed coupled-fed antenna for eight-band LTE/GSM/UMTS wireless wide area network operation in an internal mobile handset," IET Microwaves, Antennas and Propagation, vol. 7, no. 6, pp. 399407, 2013.

[6] C.-W. Yang, Y.-B. Jung, and C. W. Jung, "Octaband internal antenna for 4G mobile handset," IEEE Antennas and Wireless Propagation Letters, vol. 10, pp. 817-819, 2011.

[7] K.-L. Wong and W.-Y. Chen, "Small-size printed loop-type antenna integrated with two stacked coupled-fed shorted strip 
monopoles for eight-band LTE/GSM/UMTS operation in the mobile phone," Microwave and Optical Technology Letters, vol. 52, no. 7, pp. 1471-1476, 2010.

[8] Y. Hong, J. Tak, J. Baek, B. Myeong, and J. Choi, "Design of a multiband antenna for LTE/GSM/UMTS band operation," International Journal of Antennas and Propagation, vol. 2014, Article ID 548160, 9 pages, 2014.

[9] Y.-J. Ren, "Ceramic based small LTE MIMO handset antenna," IEEE Transactions on Antennas and Propagation, vol. 61, no. 2, pp. 934-938, 2013.

[10] F.-H. Chu and K.-L. Wong, "Planar printed strip monopole with a closely-coupled parasitic shorted strip for eight-band LTE/GSM/UMTS mobile phone," IEEE Transactions on Antennas and Propagation, vol. 58, no. 10, pp. 3426-3431, 2010.

[11] S.-C. Chen and K.-L. Wong, "Small-size 11-band LTE/WWAN/ WLAN internal mobile phone antenna," Microwave and Optical Technology Letters, vol. 52, no. 11, pp. 2603-2608, 2010.

[12] K.-L. Wong and M.-T. Chen, "Small-size LTE/WWAN printed loop antenna with an inductively coupled branch strip for bandwidth enhancement in the tablet computer," IEEE Transactions on Antennas and Propagation, vol. 61, no. 12, pp. 6144-6151, 2013.

[13] R. Valkonen, J. Ilvonen, C. Icheln, and P. Vainikainen, "Inherently non-resonant multi-band mobile terminal antenna," Electronics Letters, vol. 49, no. 1, pp. 11-13, 2013.

[14] L. Li, Z. Jia, F. F. Huo, and W. Q. Han, "A novel compact multiband antenna employing dual-band CRLH-TL for smart mobile phone application," IEEE Antennas and Wireless Propagation Letters, vol. 12, pp. 1688-1691, 2013.

[15] T.-W. Kang, K.-L. Wong, and M.-F. Tu, "Internal handset antenna array for LTE/WWAN and LTE MIMO operations," in Proceedings of the 5th IEEE European Conference on Antennas and Propagation (EUCAP '11), pp. 557-560, April 2011.

[16] J. M. J. W. Jayasinghe and D. Uduwawala, "A novel multiband miniature planar inverted $\mathrm{F}$ antenna design for bluetooth and WLAN applications," International Journal of Antennas and Propagation, vol. 2015, Article ID 970152, 6 pages, 2015.

[17] S. Risco, J. Anguera, A. Andújar, A. Pérez, and C. Puente, "Coupled monopole antenna design for multiband handset devices," Microwave and Optical Technology Letters, vol. 52, no. 2, pp. 359-364, 2010. 

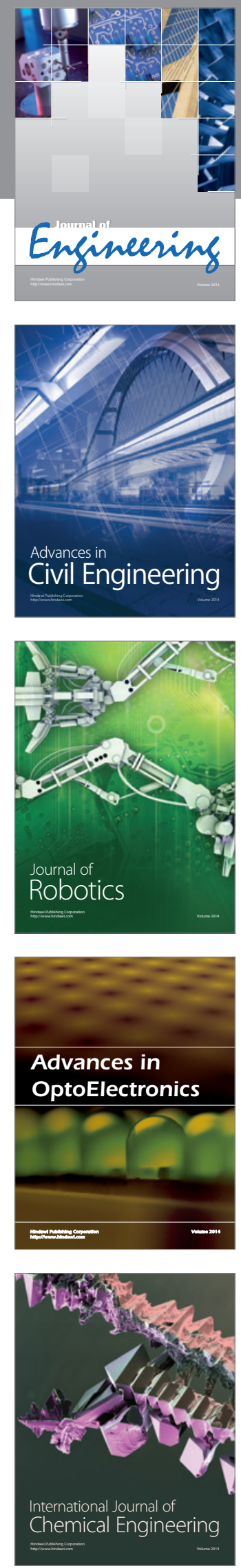

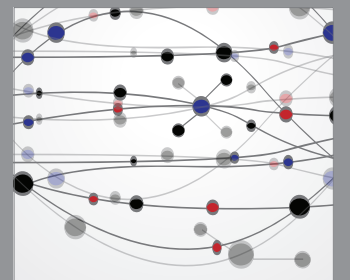

The Scientific World Journal
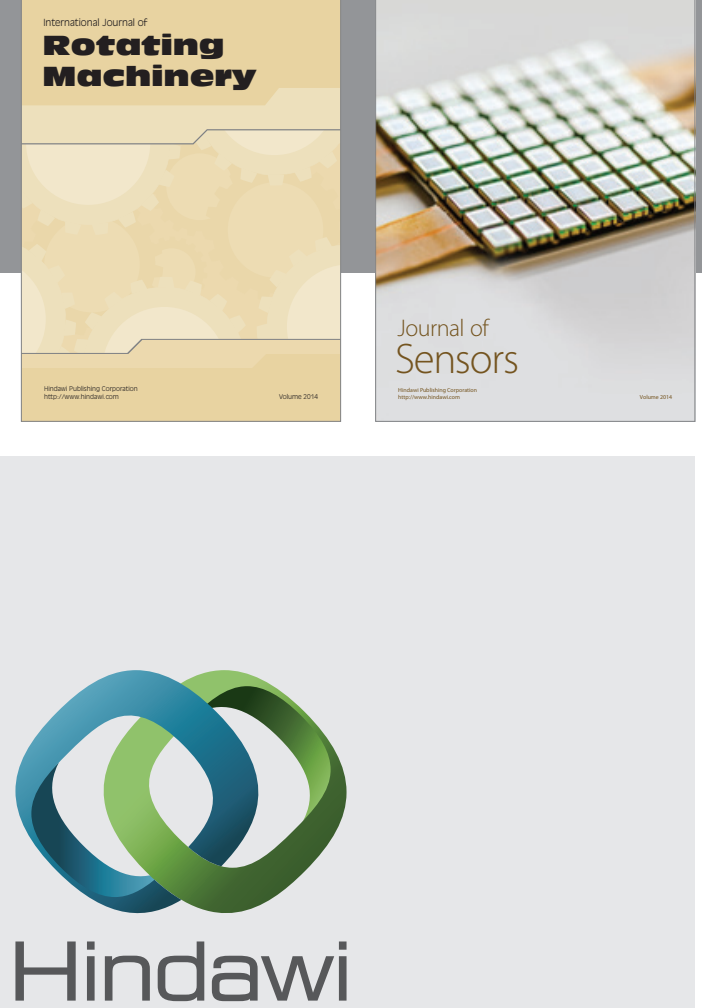

Submit your manuscripts at http://www.hindawi.com
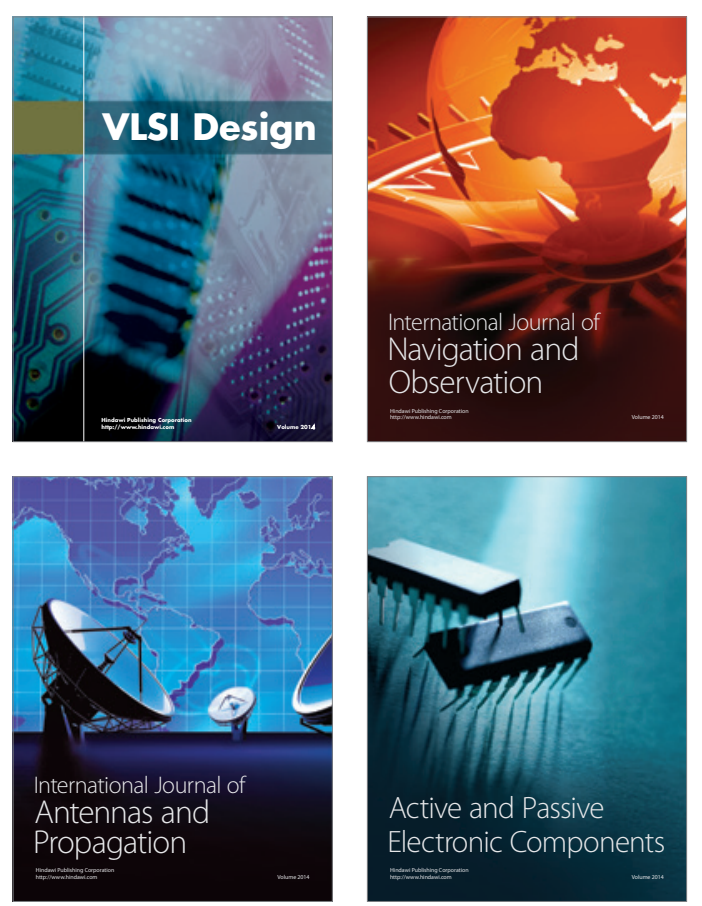
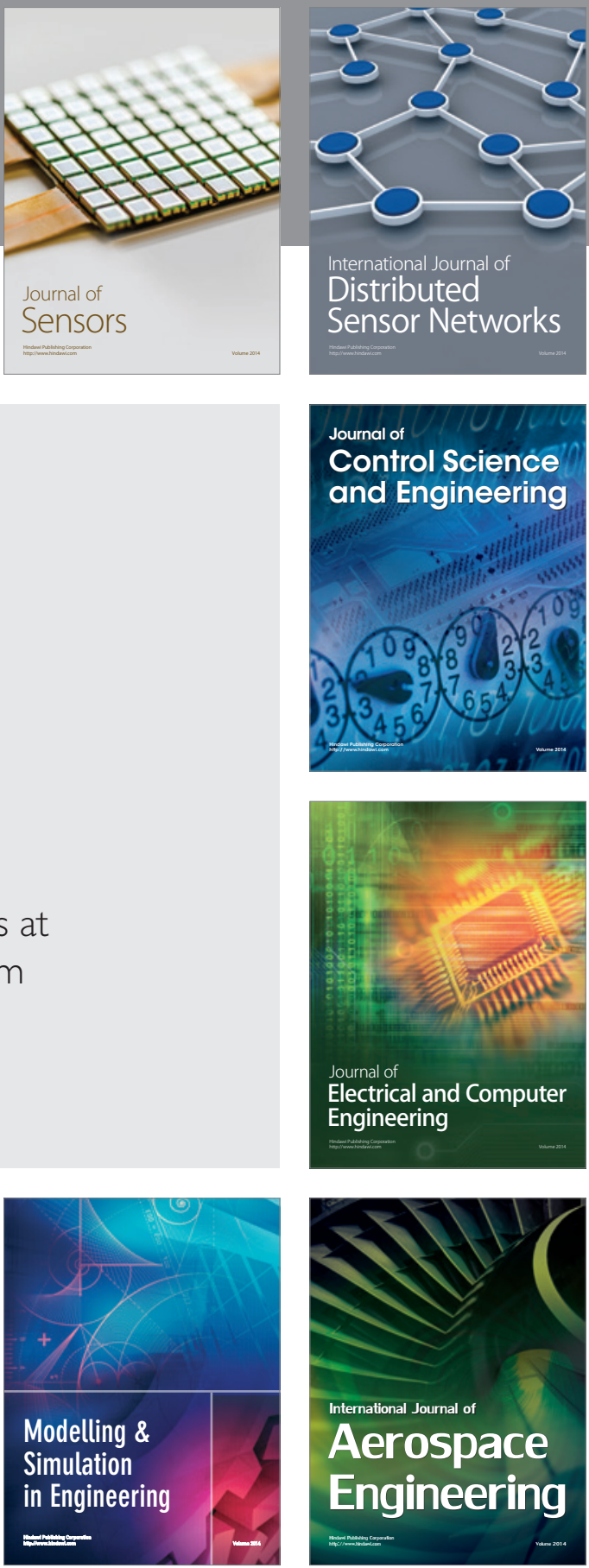

Journal of

Control Science

and Engineering
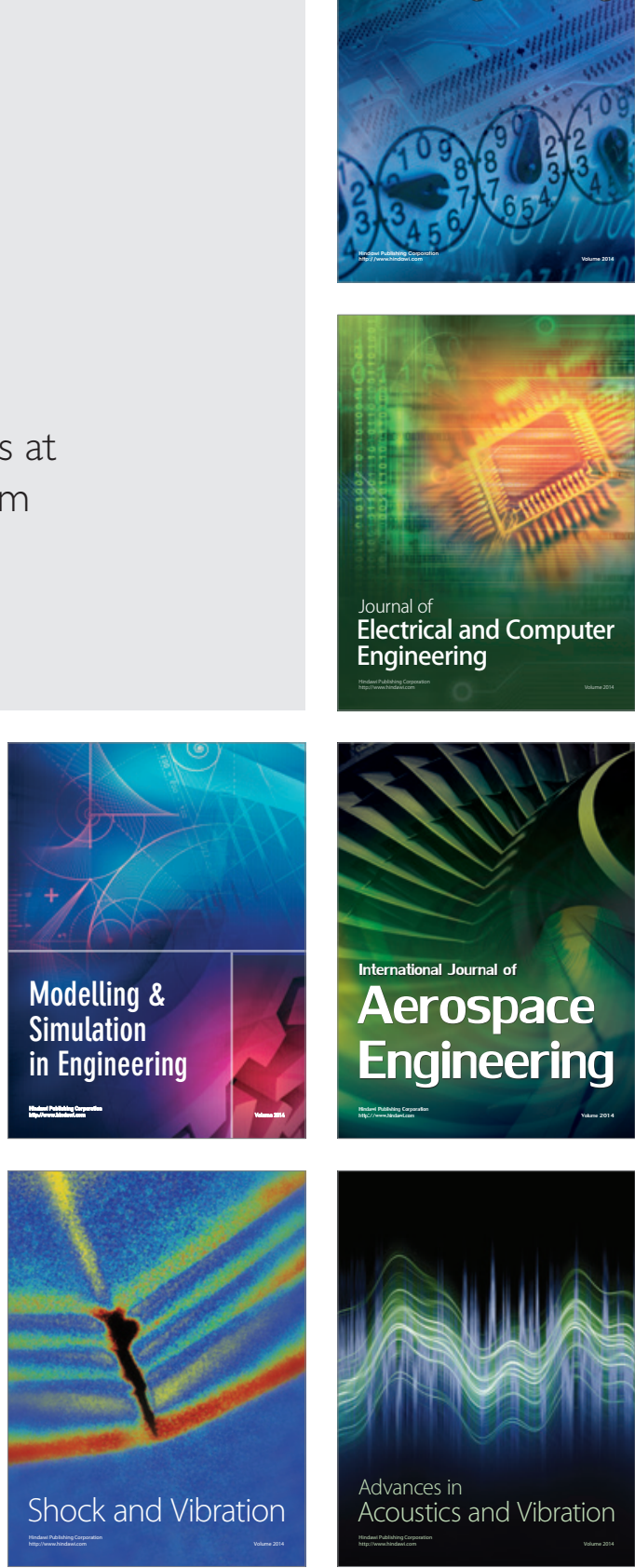